$-50 \mathrm{cat}$

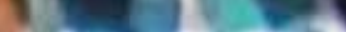




\title{
Artes visuales en Trujillo: Reflejos en silencio
}

\author{
Alfredo Alegría Alegría \\ Universidad Privada del Norte
}

El texto se refiere a la problemática del desarrollo de las artes visuales en la ciudad de Trujillo. A partir de una presentación histórica sobre el desarrollo artístico contemporáneo trujillano en las Bienales de Arte se presenta una serie de creadores tanto en la pintura, como la escultura, la fotografía y el cine. Se plantea un reclamo a los artistas: rechazar el individualismo extremo y aceptar el desafío de la realidad como forma de expresar y orientar realmente a la sociedad.

Palabras Clave: Artes Visuales, Arte Contemporáneo, Expresión Estética

This essay analyzes the problem of the development of the visual arts in Trujillo, Perú. After a historical introduction about the origins of the contemporary artistic development of Trujillo, the author presents several artists in painting, sculpture, photography and film. A claim is proposed for the artists: To reject the extreme individualism and accept the threat of reality as a way to express and guide the society.

Key Words: Visual Arts, Contemporary Art, Aesthetic Expression

¿Artes visuales en Trujillo? Interrogante marcada por una desesperanza construida a lo largo de los últimos años. Una ciudad tomada por el mercantilismo en donde los espacios culturales se han reducido por completo y si suceden eventos de esa índole se realizan en el silencio. Un silencio que poco a poco ha ido marcando el desarrollo artístico de la ciudad que, actualmente, carece de una visión y un ideal que le otorgue una identidad auténtica. De hecho, los artistas deberían asumir esta realidad y a partir de ella elaborar visiones que la interpreten y acusen. Sin embargo, estas intenciones parecen perderse en el espacio y en el concepto.

Hubo una vez en Trujillo la intención de construir un ideal cívico, de integración artística y de proyección estética. Gracias primero a las Bienales de Arte Contemporáneo $(1983,1985$, 1987) y a los Salones de Primavera (1984, 1986, 1991); luego, en base al Concurso Nacional de Pintura Coca Cola (1992-2000), al Salón Regional de la Bienal de Lima (1997-2002) y la selección regional para el concurso "Pasaporte para un artista" (1998-2010). Asimismo, el Salón de Pintura Contemporánea de Integración Latinoamericana, entre Trujillo y Cuenca, Ecuador y salones esporádicos en la ciudad. Surgió entonces una generación de artistas que llamó la atención de la crítica capitalina: el delicado neosurrealismo de Manuel Miranda Parreño; el sentido simbólico de Luis Alarcón, Tito Monzón, William Pinillos; las formas grotescas de Carlos León, el erotismo expresionista de Francisco Castillo y Humberto 
Jiménez; la fusión entre abstracción y símbolo realizada por Carlos Chávez, Juan Chávez, Coco Mora (MoraC), Rosa Benites y Pedro Méndez Encomenderos; la barroca y melancólica fantasía plasmada por Joselito Sabogal; el vaivén entre lo experimental y lo figurativo en Belinda Li, Wilo Vargas y Mao Artiaga, ganador de la Bienal de Lima de 1999. En todos ellos siempre seres perdidos en el espacio dentro de mundos imposibles; imágenes entre sombras e ilusiones; formas en distorsión sean evanescentes, estilizadas o deformadas.

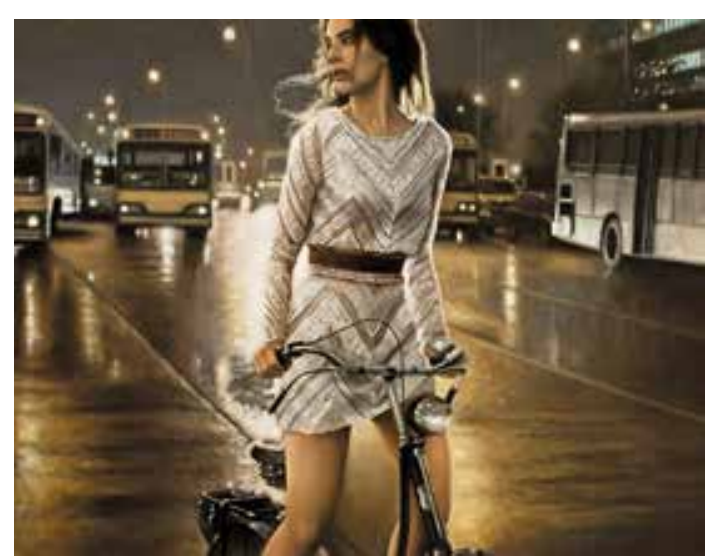

Jean Paul Zelada. Autotracking

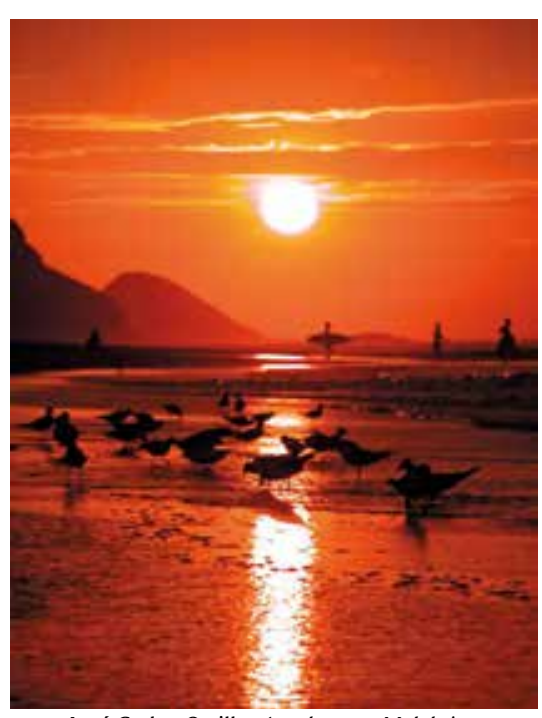

José Carlos Orrillo. Atardecer en Malabrigo

A fines de la década de 1990 aparecieron artistas cuyos trabajos rompieron de modo radical con lo que se entendía por representación e ingresaron al rumbo de lo conceptual a la fusión en instalaciones con fotografía y video. Desde hace 20 años, las experimentaciones estéticas tomaron por asalto a la ciudad gracias al trabajo de Jano Cortijo - ganador de la Bienal de Lima de 1997- y de Alice Vega, ambos tomados por el tema de la identidad ciudadana, analizando la misma en instalaciones y videos. A su lado, las visiones fotográficas cósmicas y míticas de José Carlos Orrillo. Ruta que han optado artistas del nivel de Jean Paul Zelada y Juan Carlos Alvarado Salvatierra, cuyas obras expresan estados emocionales escépticos mostrando seres deformados, situaciones incongruentes, siempre en procura de la ruptura formal y una fusión posmoderna con la fotografía. Características desarrolladas también en las instalaciones simbólicas de Gonzalo Fernández y Juan Zavaleta.

Este grupo de pintores sintió la necesidad de violentar el contexto de las imágenes, de sorprender y chocar al espectador, de rodearlo de un halo de misterio y lirismo, de desarrollar un proceso experimental de creación, sugerir la verdad interna del ser humano a través de colores, líneas, espacios e imágenes.

La forma característica de la plástica en lienzo se continuó en el lirismo de David Genell y Zuller Carrillo; los rostros, garabatos e historietas de Oscar Alarcón; la irremisible soledad expresada por Tania Castro y Wendy Castro; el interés por la naturaleza esencializada en Susana Aguilar Yauri. Asimismo, una artista liberteña es Ana de Orbegoso, que va entre Nueva York, Lima y Trujillo, con su énfasis en la forma humana defragmentada.

Muchos de ellos transitan hoy por el ámbito internacional, hecho que ha sido posible por su presencia en la red y por promotores -Anna Kesch, en especial- llegando a exponer en Latinoamérica, Estados Unidos y Europa. Buenos Aires, Caracas, Miami, Houston, New Orleans, París, Barcelona, Valencia, Madrid, Milán, Bruselas, Varsovia, Helsinki. Se han 
desperdigado por el país enseñando en escuelas de arte o academias de arte contemporáneo en la capital o en otras provincias. Algunos residen en el extranjero, muchos en Lima, hay quienes han callado como Mao Artiaga, algunos persisten y hasta retornan. Sin embargo, la característica es la desintegración, la inexistencia de un movimiento unido como en los años 90 con una ideología planteada y una ilusión.

Representantes de una generación comprometida con la expresión y el análisis del mundo que le rodea, se plantearon la creación estética como la realización objetiva de propuestas conceptuales. En ese rumbo, el artista trujillano ha divagado entre la expresión, la fantasía, el sentido de la construcción de la forma, en el deseo de transmitir realidades simbólicas con un común denominador: la soledad. Seres fantásticos, naturalezas esencializadas, estructuras abstractas, desnudos femeninos en universos misteriosos, colores angustiados, manchas de color como gestos emocionales de mundos caóticos o ambiguos. Caminos que transcurren desde la convicción en el ideal a la paradójica afirmación de la negación de la vida. Paulatinamente en esta primera década del nuevo siglo empezaron a enfrentar el desafío de la realidad.

En este desafío, pareciera que la pintura viene siendo desplazada por la necesidad de expresarse en la fotografía, que se hace eco del sentido experimentalista del arte contemporáneo. Medio que es tratado de modo que remarque el hecho reflexivo y en procura de transmitir el concepto de instantaneidad, el sentimiento de búsqueda de la trascendencia de lo intrascendente e instantáneo. Transmite la fotografía una particular magia: la técnica se eleva y traduce todo un proceso sensorial que el artista transforma en una auténtica construcción intelectual. Este carácter se observa en las fotografías de Carmen Hoyle -que captura el movimiento del fuego como personajes danzantes hechos de luz- y Perla Callirgos -tomada por visiones de la naturaleza sea en paisajes realistas y exactos en claroscuro o formas terrestres como seres fantásticos-. Asimismo, los dolorosos cuerpos destruidos y formas incongruentes de Omar Miñano.

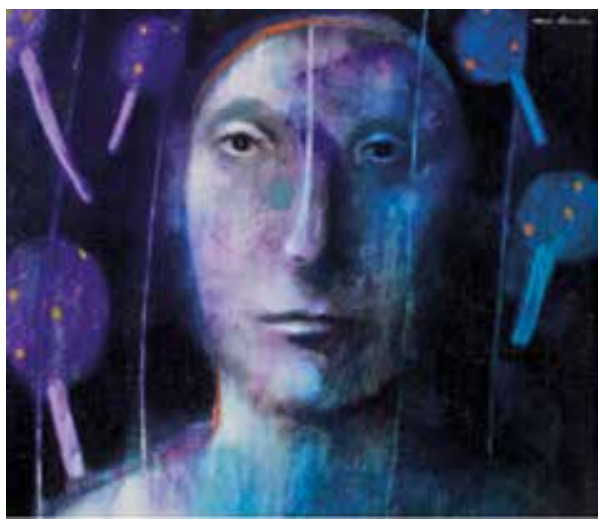

Oscar Alarcón. Personaje en azul

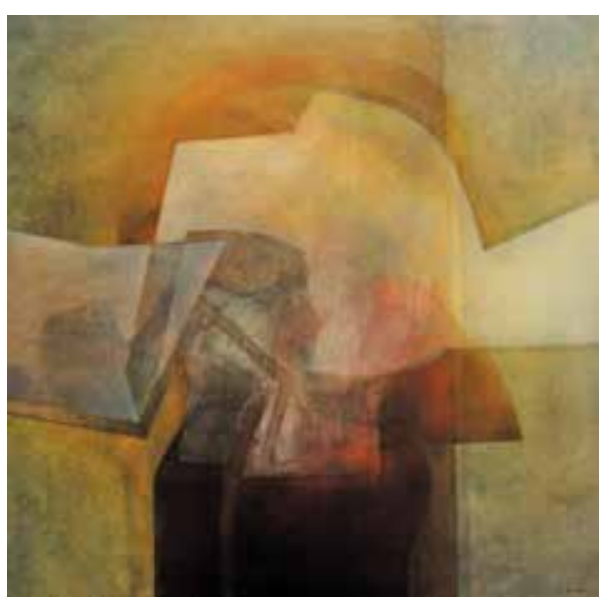

Adolfo Asmat. Santuario

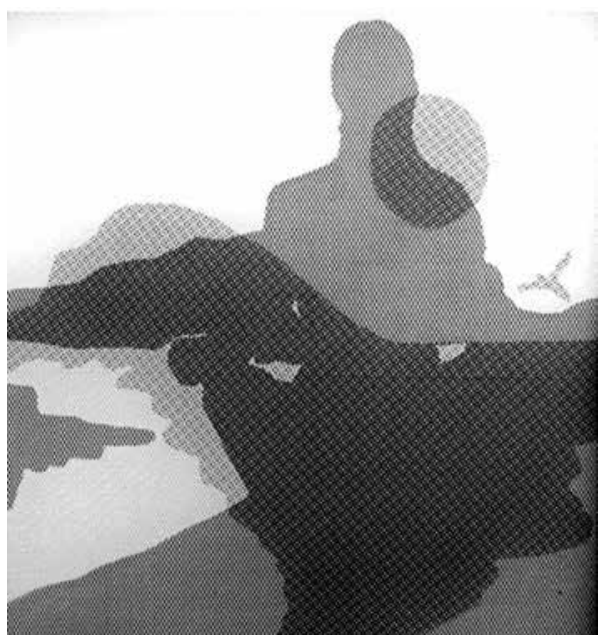

Wendy Castro. Tampoco soy yo, tinta sobre organza 


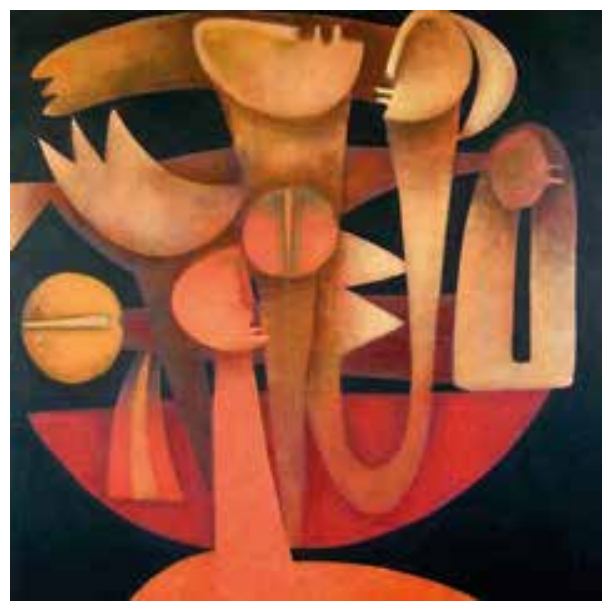

Carlos León. Construcciones de manantial

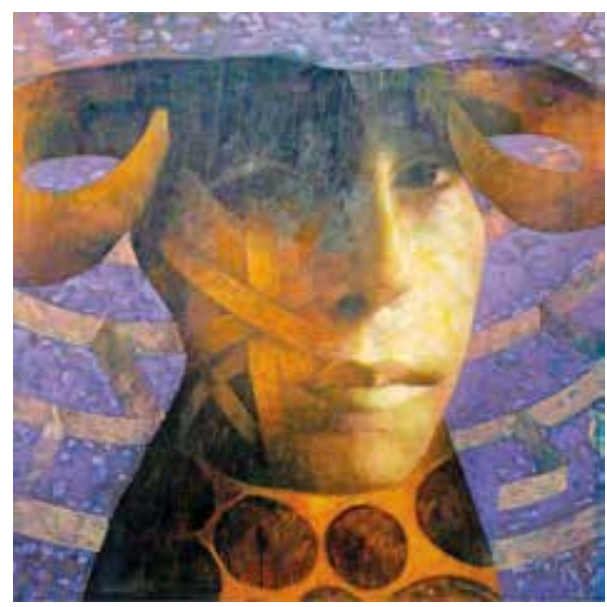

Joselito Sabogal. Caligramas escritos sobre la piel

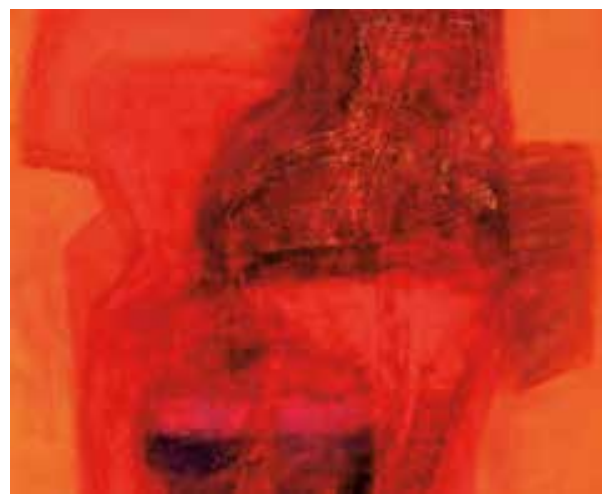

Socorro Mora MoraC. Trashumantes, óleo sobre lienzo
Paulatinamente, el público ha ido aprendiendo códigos que le permiten ingresar de a poco al extraño mundo de la expresión artística actual. ¿Arte? ¿Qué es arte? Los jóvenes se sienten hoy más cercanos a las instalaciones, los videos y formas urbanas que a la expresión tradicional en lienzo. Esta juventud viene asumiendo que la expresión estética es actualmente un espacio multimedia e interactivo donde el espectador se convierte en partícipe y hasta en elemento del concepto.

Un ejemplo es la instalación "Habitat", de Héctor Lozano "Fasalá" y Shoshi Chong (2015): Ambos transformaron el espacio de la galería "Impromptu": Un muro tratado con tierra al estilo de un inmenso cuadro de Jackson Pollock. Fotografías del cuerpo humano defragmentado, con aspectos eróticos explícitos en tono lírico o formas corporales en movimiento, completamente difuminadas. Formas geométricas místicas colgaban del techo y el público caminaba entre maniquíes.

Otro aspecto es el uso multimedia en diversas instalaciones aún con intervenciones sonoras, texturas o con reflejos lumínicos. Sin embargo, hay que tomar en cuenta que este carácter multimedia puede conducir tanto hacia la libertad pero también generar un desorden conceptual. Este caos conceptual tan propio de los artistas de hoy resulta un testimonio de la época y de la crisis humana que agobia la sociedad. Pese al esfuerzo que realiza por comprender, el público se siente distanciado y perplejo buscando una validez para lo que observa, lo que por momentos pareciera tener un sentido críptico.

El último acontecimiento verdaderamente importante en la plástica trujillana fue la exposición "Ciudad Fantasía" (2014): Videoinstalaciones, fotografías y obras plásticas que denunciaban la mediocridad espiritual en que se ha sumergido la ciudad desde su dirigencia. Muestra conceptualmente desintegrada aunque con una temática genérica: la acusación política directa a la comuna, los políticos y el mercantilismo. Apareció allí un grupo singular: Trujillo Kitsch. El tema fue también el rechazo a la supuesta identidad turística promocionada en la marinera y la primavera. La muestra fue realmente 


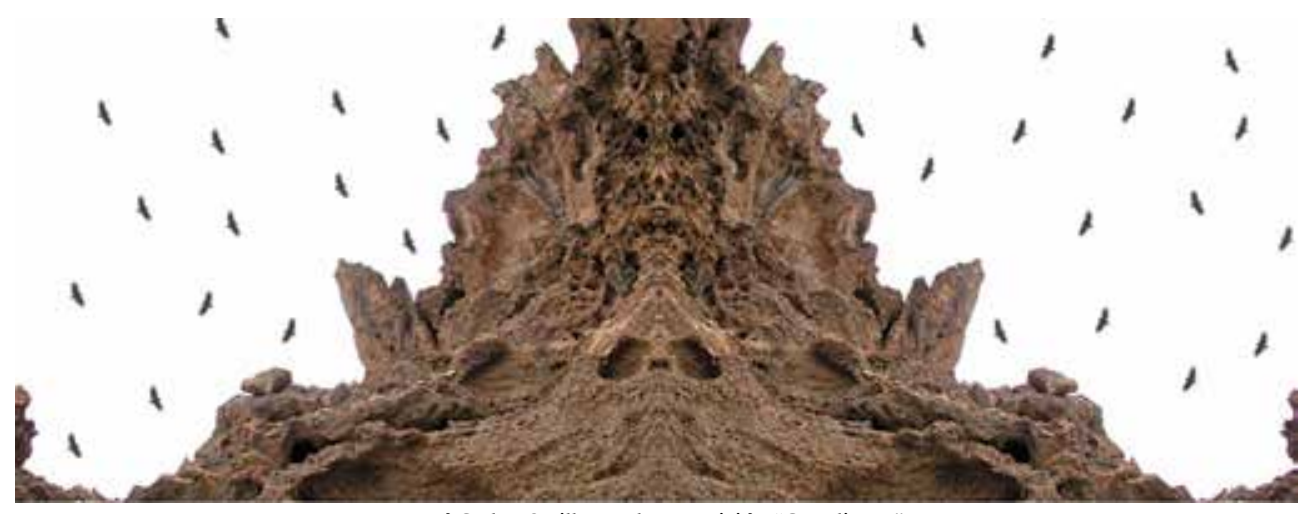

José Carlos Orrillo. De la exposición “Guardianes”

censurada y se la retiró casi inmediatamente sin razones válidas. Un reflejo de lo que hoy se vive en el hecho cultural. ¿Cómo puede el artista expresarse en un contexto tal? Y sin embargo, no hubo una respuesta. Ese intento de unidad de artistas -liderado entre muchos por Alice Vega y Rosa Benites- no ha continuado.

También la escultura tuvo un intento de desarrollo que fue impulsado por una serie de Salones de Escultura que integraban artistas de Trujillo y "del interior", como se dice en Lima. Fueron salones en el vacío a pesar de las buenas intenciones. Aún así se puede rescatar a Valdemar Castillo -con trabajos en piedra en una abstracción purista- y Beatriz Suárez: desnudos deformados en cera o en bronce.

Por supuesto que se mantienen artistas tradicionales de la escuela antigua: Demetrio Saldaña, tan pulcro pero marcado por un pintoresquismo y a veces propuestas expresionistas; Carlos Rodríguez, que reside en Colombia donde es reconocido y caracterizado por figuras geometrizadas y desnudos opulentos en mundos selváticos; el realismo persistente de los paisajes urbanos de Rómulo Azabache.

¿Dónde están realmente los artistas trujillanos? Porque da la sensación que la ciudad es el lugar donde surgen y de la que inevitablemente se apartan al sentir que es un espacio demasiado pequeño para su autorrealización. En todo caso, quienes están aquí no han logrado conformar un grupo artístico joven completamente nuevo que resuma las tendencias actuales en forma trascendente. Grupo que apareció con el manifiesto de "Grito" hace 25 años, de donde se desprende todo el desarrollo actual. Actitud que determina un vacío que es imprescindible llenar.

Dejando a un lado, los nombres mencionados que pertenecen a la década pasada, la novedad

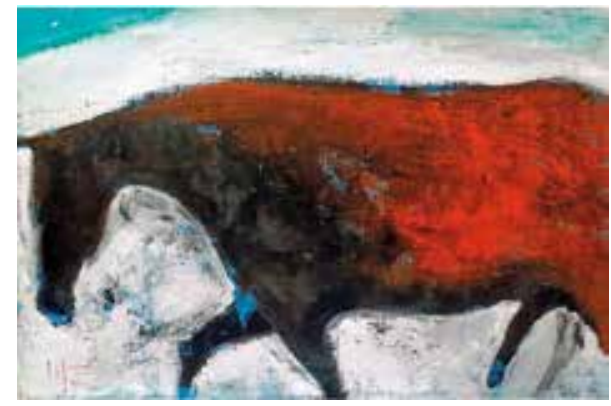

Pedro Méndez. Encomenderos

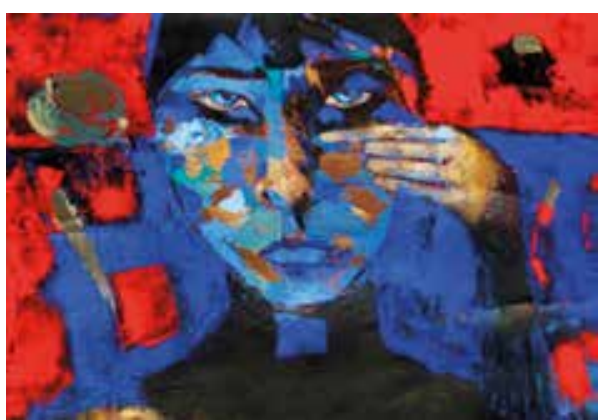

Humberto Jiménez. Composición, óleo sobre lienzo 


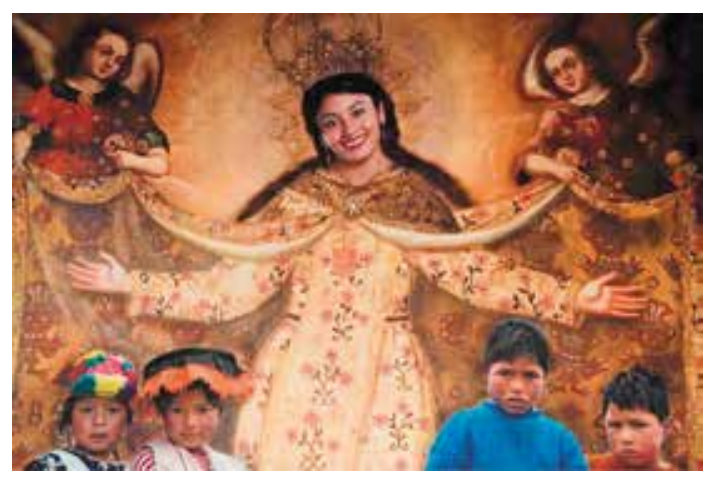

Ana de Orbegoso. Virgen Urbana

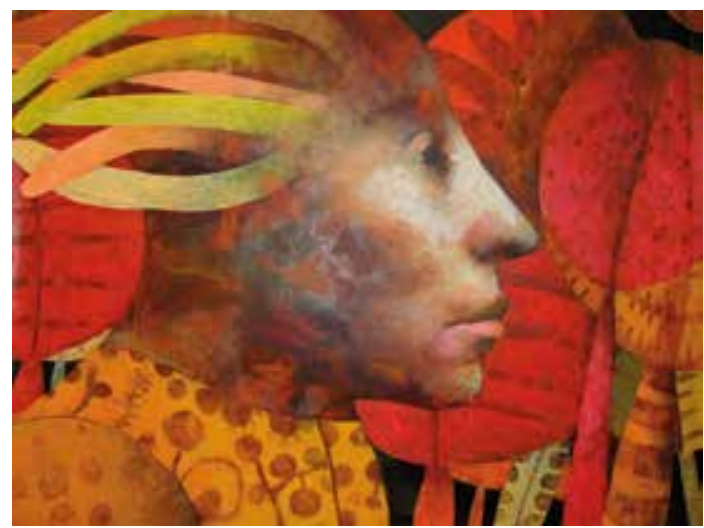

Joselito Sabogal. Catalejo con sabor a sed en mar incierta

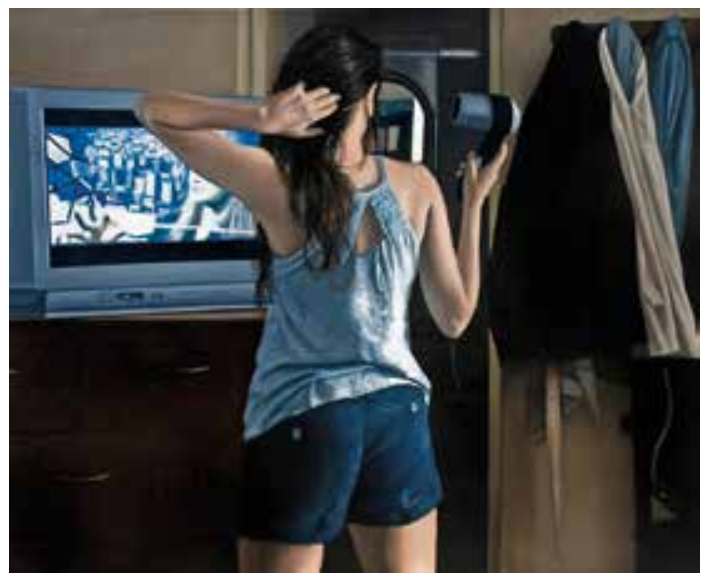

Jean Paul Zelada -si así puede llamarse- proviene de las universidades -Universidad Privada del Norte y Universidad Antenor Orrego-. Los artistas plásticos que hoy salen de la Escuela de Bellas Artes de la ciudad prefieren recorrer lugares comunes, buscando una novedad que no es tal y sin una solidez conceptual. Es la peligrosa aceptación convencional de cualquier experimento: ¿tradicionalidad de lo contemporáneo, convencionalismo de lo informal?¿Hasta qué punto el artista tiene derecho de decidir su estilo basado en la sugerencia de modelos artísticos sin relación directa con nuestra realidad? ¿La globalización ha anulado la identidad particular de los pueblos?

Es así que muchos nuevos artistas que optan por la pintura en lienzo corren el riesgo de perderse en gestos que fueron válidos en el Perú de los años 60 y 70 y -tal vez- para cierto neoexpresionismo de los 80 y comienzos de los 90 pero que hoy se tornan vacuos. Ya no resulta válido trabajar según las pautas de la antigua modernidad. Vivimos la posmodernidad, un momento histórico difícil caracterizado por el relativismo cultural total.

En un país como el nuestro, tan lleno de problemas humanos, detenerse solo en la belleza formal del color, la singularidad de los conceptos o la sorpresa de lo absurdo llega a ser irresponsable. No vivimos en el tiempo del neo dadaísmo y el nihilismo artístico. Nuestro alrededor es demasiado terrible para que quienes tienen el don especial de ponerlo en evidencia en imágenes escojan la evasión hacia la seguridad de un mundo interno y -defendidos por un extraño hermetismodeserten de su responsabilidad como portadores de denuncia, orientación y pensamiento.

Pienso que los nuevos artistas plásticos trujillanos han aceptado enfrentarse al desafío de la realidad, vista en forma propia y no sólo a través del cristal metropolitano. Interiorizar que pertenecen a una sociedad que requiere mensajes que enriquezcan su espíritu. No pueden sumergirse en la torre de marfil contemporánea. El llamado es entonces a asumir 
una lucha real y directa. Una lucha contra el vacío conceptual; contra el pragmatismo de los tiempos y del sistema pero, ante todo, contra sí mismos.

Si de artes visuales se trata hay que tomar en cuenta al cine que hoy está cobrando un desarrollo interesante en Trujillo, con un festival nacional y directores importantes: Daniel Rodríguez Risco -"El vientre"- y Omar Forero, reconocido por "Chicama”.

Y así viene transcurriendo el quehacer de las artes visuales trujillanas. Ilusiones expresadas en gestos individualistas y solitarios o bien como reflejos de un mundo materialista y ciego. Quehacer que sucede en el silencio, sin el apoyo suficiente, sin la posibilidad de una crítica -casi ya no existe esa posibilidad en el diario de la ciudad-y difundida en parte gracias a las redes sociales.

No quisiéramos repetir con José Eulogio Garrido -quien observaba con desesperación a un Trujillo destruido y olvidado- que a la ilusión de ciudad la "ha tumbado el tiempo...se la ha llevado el viento". Frente a esta desesperanza por el actual caos social, solo puede responderse con la fe en la posibilidad de construir el futuro con belleza y con valores. Necesitamos nuevamente de soñadores. Necesitamos de líderes. Necesitamos crear de nuevo a Trujillo. Siempre las historias comienzan con "hubo alguna vez". La tarea que se nos impone es continuar la historia legada, retomar el camino trazado y dignificar este rumbo para las generaciones por venir. La sociedad peruana se ha tornado cada vez más compleja y difícil de descifrar. Este enigma surge así ante los creadores plásticos trujillanos como un reto a asumir. Mensajeros de ilusiones y deseos, tienen el deber de forjar en sus obras conceptos que interpreten y propongan caminos a una sociedad angustiada y ansiosa. Poesía y verdad, realidad y ensueño, desafío y acción de una juventud que forja su propio destino.

\section{Referencias bibliográficas}

Alegría Alegría, Alfredo

2003 Plástica Contemporánea en Trujillo: Bienales de Arte y Salones de Primavera. Trujillo: Gráfica Real. 